Thus, the evidence seems to indicate that the Burmese amber fauna is Eocene, and older than the Eocene (Bartonian) beds which have produced fossil insects in the south of England.

At this point, however, a new problem is introduced. A few days ago I received from Mr. Swinhoe a number of beads of extremely pale and pellucid amber containing well-preserved insects, all different from those previously described. These insects include a small bee, which seems not to differ at all from the common living Indian Trigona laviceps Smith. The other amber contained no ants, but this includes a worker of Crematogaster, workers of Pheidole, and males of Monomorium. I also find a winged termite, a psyllid, a fly of the genus Phlebotomus, some acalyptrate muscoid flies, a mycetophilid, some small spiders, etc. So far as can be seen, this is a modern series of types. Mr. Swinhoe found that the beads, when he purchased them, had been artificially coloured to enhance their value, and he had this colouring matter removed. He learned that several stained necklaces had been imported from China, so he could not be sure that the material was really from Burma. At one time he even wondered whether the specimens could have been included in artificial amber, as is sometimes done. He decided that this last suspicion was unfounded, and I quite agree. His letter ends: "Probably this light amber comes from a locality a few miles off." My own opinion is that this light amber (or copal) is of very recent origin, not earlier than Pleistocene, and contains a fauna which doubtless consists mainly (at least) of species still living. The bee which I recently described as Meliponorytes (?) devictus probably belongs to this material, and not to the Eocene amber. We may surmise that we have the product of some Dipterocarpaceous tree allied to Vateria; something similar to Miss Ruth Holden's Dipterocarpoxylon burmense, based on fossil wood from Burma. More exact information on this matter is greatly to be desired.

University of Colorado, May I, I922.

$$
\text { T. D. A. Cockereli. }
$$

\section{Radium Synthesis of Carbon Compounds from Air.}

Now that photo-synthesis is attracting special attention it may be interesting to record some recent preliminary experiments on the production of synthetic carbon compounds by the action of radium rays on atmospheric air. Under normal conditions of temperature and pressure, it seems evident that this radio-synthesis is capable of producing carbon compounds apart from living cells, and without the agency of solar radiation.

The experiments arose from an observation, made some nine years ago, during an investigation of the curvature of thin plates of mica when acted upon by radium. After long exposures-some weeks in duration-I noticed a deposit of brown patches, mere specks, on the uppermost side of the thin strips, that is, the side which became concave during a-ray bombardment.

As this deposit was found not to be responsible for the bending, it was not mentioned in the resulting paper (Journal Röngten Society, No. 44, vol. xi., "Alpha Ray Effect Mechanical "), but left for future investigation, which eventually had to be abandoned on account of urgent war work.

Having recently made further experiments, I find that the deposits can be detected more quickly, and better observed, by using freshly drawn fibres of quartz or glass, diameter about 0.04 millimetres. Several of these may be spaced about I $\mathrm{mm}$. apart, supported on a framework immediately over the radium salt, about one-eighth of an inch above the uncovered radio-active surface (one or two milligrammes of radium or mesothorium is sufficient).

The whole arrangement should be put into a clean cardboard box (about one litre capacity, to reduce convection currents), with loose fitting lid, which is then put away in a dark room. After remaining undisturbed for a week, it will be seen, using a Coddington lens (or better if transferred to a microscope with one-inch objective), that the fibres are covered with a clear white viscid liquid film, which is beginning to gather up into beads, or droplets, at more or less regular distances. After a further exposure of a few days, it will be found that all the droplets have increased in size, some having reached a pale sherry colour. Further exposure leads to increase in size, eventually resulting in dimensions about double the diameter of the fibre. The colour changes may be from white to sherry, red, then dark brown, after about six weeks' exposure ; later a little irregularity of contour of the brown droplets may be noticed, showing that the liquid is tending to solidify with irregular contraction; fresh deposits may appear in the interspace between old droplets, so that a fibre may contain droplets in all stages.

It is evident that the first liquid product, colourless at the beginning, is soon oxidised in the ozone which is produced by the a-rays. By reason of the time required and the minute quantity of the first product, it is difficult to make tests before oxidation has taken place to some extent.

Preliminary microscopical examination of the final dark brown product, which becomes a strongly adherent scaly deposit, on a mica strip (after nine years), demonstrated that the brown deposit was insoluble in alcohol and chloroform but dissolved in hot water. On evaporation of this solution a brown film was formed which cracked into scales on drying. This film became carbonised on heating, at about the same temperature as a particle of gum acacia, on the same electric hot-plate.

So far, I have not obtained deposits by using $\alpha-\beta$ or $\gamma$-rays, either separately or in combination. The gaseous emanation of radium seems to be necessary, which points to the probability that the radium products of short period are chiefly concerned in the synthesis, or in facilitating condensation on solids. On this point, and on the physical aspects, further experiments are in progress, but it is very desirable that the chemical examination of the products should be made by others with better facilities than those I possess for dealing with very minute quantities. Possibly increased production may be obtained by increasing the proportion of water vapour and carbon dioxide in the air. I should be very glad to know of any work already done bearing on the subject. Have such products ever been found in the atmosphere? If ultra microscopical, rain may contain some.

I 56 Clapham Road, London, S.W.9.

$$
\text { F. Harrison Glew. }
$$

\section{Cephalic Index and Sex.}

IN NATURE of March 23, p. 389, I find the statement-in a summary of a paper by Miss R. M. Fleming -that " British women show more development of pigment, brachycephaly, and prognathism than do men."

As to the cephalic index I see quite the same in Arthur Thomson and Randall-MacIver's interesting account of skulls from "The Ancient Races of the Thebaid "(Oxford, I905) ; and probably this " more development of brachycephaly "in women is a general law.

$$
\text { No. } 2744 \text {, VOL. IOg] }
$$


But, as I pointed out in 1907, in my Danish paper, "Om Kortskaller og Langskaller" (Oversigt over D. K. Danske Videnskabernes Selskabs Forhandlinger, T907) -also published in a German translation in " Archiv für Rassen- und Gesellschafts biologie" (IV., rgo7) - such indications need correction because of the correlation between absolute length of skull and cephalic index: the index diminishing greatly with increasing length.

I will here reproduce only one of the concluding tables of my paper in which I have given computations of the English authors' splendid material. The whole of the material (775 males and 754 females) gives for the skulls these averages:

Males: $\quad \mathrm{L}$., I $8.426 \mathrm{Br}$., I3.536 Index, 73.48

Females: L., 17.682 Br., 13.187 Index, 74.58

i.e. showing " more development of brachycephaly" in women.

But if we compare what ought to be compared, namely, the skulls having the same lengths, we find quite different results.

Comparisons of the cephalic index in men and women within the same classes of absolute length are given in the following table:

\begin{tabular}{|c|c|c|c|c|}
\hline \multirow{2}{*}{\multicolumn{2}{|c|}{ Limits of Length-Classes. }} & \multicolumn{2}{|c|}{ Index of Skulls. } & \multirow{2}{*}{$\begin{array}{l}\text { Difference and } \\
\text { Mean Error. }\end{array}$} \\
\hline & & Male. & Female. & \\
\hline $\begin{array}{ll}\text { I7 } & \mathrm{cm} . \\
\text { I7.5 } & , \\
\text { I8 } & ", \\
\text { I } 8 \cdot 5 \quad " \\
\text { I9 " }\end{array}$ & $\begin{array}{l}\cdot \\
\cdot \\
\cdot \\
\cdot\end{array}$ & $\begin{array}{l}77 \cdot 34 \\
75 \cdot 40 \\
73 \cdot 88 \\
72 \cdot 42\end{array}$ & $\begin{array}{l}75 \cdot 86 \\
74 \cdot 28 \\
73 \cdot 18 \\
7 \mathbf{I} \cdot 24\end{array}$ & $\begin{array}{l}\mathrm{I} \cdot 48 \pm 0 \cdot 47 \\
\mathrm{I} \cdot \mathrm{I} 2 \pm 0 \cdot 29 \\
\mathrm{O} \cdot 7 \mathrm{O} \pm 0 \cdot 30 \\
\mathrm{I} \cdot \mathrm{I} 8 \pm 0.5 \mathrm{I}\end{array}$ \\
\hline
\end{tabular}

The same divergence runs through all special series of the material. The same class of absolute length of head (again correlated with the height of body and so on) shows more development of brachycephaly in men than in women!

In this short letter I need not enter into the various questions concerning cephalic index and heredity, Mendelism, etc.

University of Copenhagen.

THe point which Prof. Johannsen raises is interesting, though absolute measurements on men and women are scarcely comparable. Absolute measurements on women are not only smaller than those on men of the same type, but also differ in their relationships. As pointed out in a summary of our measurement results in Man for May 1922, a range of absolute head length $\mathrm{I} 8 \mathrm{I}-\mathrm{I} 93 \mathrm{~mm}$. in women of a certain race type corresponds with a range of absolute head length 194-204 $\mathrm{mm}$. in men of that race type. It will thus be seen at once that a comparison of a man and a woman having the same absolute head length means a comparison between two people not only of different sex, but, also of different race type. In such a comparison one gets a woman towards the long headed end of the series compared with a man towards the short headed end of the series for that sex. The smallest absolute measurements for head breadth are among women, for all women's measurements are small, but at the same time these heads need not necessarily be narrow proportionately to their length, which may also be very small. Classifying race types on the basis of summation of characters our thousands of measurements undoubtedly show that women's heads show greater velative breadth (i.e. are not so oval in shape) as those of the men nearest to them in general features.

In conclusion, may I refer to Prof. Johannsen's mention of length of head correlated with height of body. Our results have gone to show that on the whole the greatest absolute length of head is to be found in a race type the height of which is distinctly sub-normal. The longest headed man I have meassured is of this type and is under five feet in height. This of course may not apply to the race types Prof. Johannsen has measured, but it would be interesting to have his observations on the point.

$$
\text { R. M. Fleming. }
$$

\section{The Organisation of Knowledge.}

REgaRding the remarks made in Nature of May 6 on the address of Dr. F. I. Hoffman at the American Association, it might be suggested that the organisation of facts for commercial uses is of a different order than the organisation of knowledge for the purpose of understanding the operations of Nature or of ascertaining a particular law of cause and effect. A man who collects data may, or may not, have imagination. A man may also classify facts quite mechanically according to a scheme laid down. The successful "business organiser," however, usually has a new plan and sets others to work to collect facts for him to organise or re-organise. He knows at the start why he wants the facts and how to use them. Imagination is required by such an organiser because he has to adjust his methods not only to his data but to human beings and a changing world.

Mathematics, however, in the Pythagorean sense of Mathesis, certainly is not necessary for the actuaries' arithmetical operations. But, so far, neither actuaries nor the inductive method of inquiry alone have been able to predict epidemics of disease, revolutions or wars, not to mention earthquakes and tidal waves; nor have they anticipated discoveries of fundamental laws, such, for example, as that of Dalton's doctrine of atomic proportions or Faraday's law of electromagnetic induction. Dalton, we know, was a mathematician and was not personally engaged in collecting evidence; his laboratory work was insignificant. Faraday himself stated that he had reached his conclusion by a process of thought and $k n e w$ it must be true before he obtained the evidence by experiment. Who, even then, suspected the industrial results that followed in later years through the application of the principle by others? It is to mathematics in the original Greek sense of principles or proportions (not calculation merely) that we owe the really epoch-making discoveries of science. Even inventions are not the result of examining facts. A mechanical genius has a knowledge (instinctive or mathematical) of a law he tries to demonstrate practically; he does not attempt to formulate a law from a collection of facts. The evidence proves the law to the senses; but a law is not created nor even discovered by evidence. Inductive science has been necessary in order that we should become acquainted with the different kinds of materials and variety of species, etc., in the world, for, before Bacon's instructions had been carried out, there was no opportunity to apply the laws of Nature (understood, without doubt, in a general way by Bacon himself) even when a genius with mathematical imagination saw them in his thought. Inductive and deductive methods are each ineffective without the other.

Again, the history of modern chemistry and physics does not support the contention that the laws of mechanical engineering were evolved by rule-of-thumb experiments amongst primitive peoples before, for instance, the pyramids could be built. Modern hydraulic engineering arose in the mind of one Carnot, a mathematical genius who demonstrated its laws 